\title{
Is isolated systolic hypertension an indication for renal denervation?
}

\author{
Yutang Wang * \\ School of Applied and Biomedical Sciences, Federation University Australia, Mount Helen, VIC, Australia \\ *Correspondence: yutangwang000@gmail.com
}

Edited by:

Carolyn J. Barrett, University of Auckland, New Zealand

Reviewed by:

Rohit Ramchandra, Florey Neuroscience Institute, Australia

Mark Knuepfer, Saint Louis University School of Medicine, USA

Keywords: blood pressure, clinical trials, isolated systolic hypertension, renal artery stenosis, renal denervation

\section{A commentary on}

Reduced effect of percutaneous renal denervation on blood pressure in patients with isolated systolic hypertension

by Ewen, S., Ukena, C., Linz, D., Kindermann, I., Cremers, B., Laufs, U., et al. (2014). Hypertension. doi: 10.1161/HYPERTENSIONAHA.114.04336

Ewen et al. recently reported in the journal Hypertension that they investigated, for the first time, the effect of renal denervation on blood pressure in 63 patients with isolated systolic hypertension (Ewen et al., 2014). The authors concluded that renal denervation reduced office and ambulatory blood pressure in patients with isolated systolic hypertension (Ewen et al., 2014). However, this conclusion may not be drawn, as renal denervation may not decrease ambulatory blood pressure in these patients. The potential risk of renal denervation may overweigh its benefit in patients with isolated systolic hypertension. Therefore, adjusted drug treatment may be recommended to these patients before renal denervation.

Ambulatory blood pressure monitoring is the gold standard to diagnose true hypertension and removes the white coat effect (Hermida et al., 2013). Ambulatory blood pressure is superior to office blood pressure in predicting cardiovascular events (Staessen et al., 1999) and mortality (Dolan et al., 2005). The 24-h ambulatory systolic blood pressure in these 63 patients in Ewen et al.'s report decreased by $8 \pm 8$ and $7 \pm 8 \mathrm{~mm} \mathrm{Hg}$ at 6 and 12 months respectively after renal denervation. However, this study lacked a control group as the authors pointed out as a limitation. It has been reported that the sham procedure reduced 24 -h ambulatory systolic blood pressure by $5 \pm 15 \mathrm{~mm} \mathrm{Hg}$ at 6 months (Bhatt et al., 2014). Therefore, compared with the sham procedure, renal denervation may not decrease ambulatory blood pressure in those patients with isolated systolic hypertension.

Consequently, the risk posed to patients with isolated systolic hypertension by renal denervation may overweigh the minimal benefit of renal denervation via lowering blood pressure. For example, renal artery stenosis after renal denervation is of concern. The renal artery stenosis rate in the Symplicity HTN trials $(N=45$, 106, and 535 for the Symplicity HTN-1, HTN-2, and HTN-3 trials, respectively) ranges from 0.3 to $2.2 \%$ (Krum et al., 2009; Esler et al., 2010; Bhatt et al., 2014). However, more and more studies with a smaller sample size (Worthley et al., 2013; Versaci et al., 2014) and case reports (Kaltenbach et al., 2012; Vonend et al., 2012; $\quad$ Aguila et al., 2014; Bacaksiz et al., 2014; Chandra et al., 2014; Pucci et al., 2014) showed relatively higher rates of development or progression of renal artery stenosis after renal denervation. Ewen et al. did not observe any hemodynamically significant renal artery stenosis in these 63 patients with isolated systolic hypertension within 12 months (Ewen et al., 2014). However, ultrasonography, which was used by the authors, has limitations in detecting renal artery stenosis (Zhang et al., 2009; Lao et al., 2011).
Renal denervation is regarded as a last resort for patients with resistant hypertension (Persu et al., 2012). It is reported that about $9 \%$ of adults with hypertension suffer from resistant hypertension (Persell, 2011), which is often defined as elevated blood pressure despite treatment with at least 3 antihypertensive agents including a diuretic at maximal tolerated or highest recommended doses (Bohm et al., 2014). The prevalence of resistant hypertension is likely overestimated due to drug non-adherence. For example, blood pressure in 20 of 65 patients with resistant hypertension was normalized after witnessed intake of antihypertensive drugs (Fadl Elmula et al., 2014). Resistant hypertension has been classified as "true" resistant hypertension if blood pressure is still elevated after witnessed intake of antihypertensive drugs (Fadl Elmula et al., 2014). Blood pressure in some patients with "true" resistant hypertension could be controlled by adjusted drug treatment. For example, Fadl Elmula et al. reported that adjusted drug treatment significantly decreased ambulatory systolic blood pressure from $152 \pm 12 \mathrm{~mm} \mathrm{Hg}$ at baseline to $133 \pm 11 \mathrm{~mm} \mathrm{Hg}$ at 6 months in 10 patients with "true" resistant hypertension (Fadl Elmula et al., 2014). In addition, adjusted drug treatment lowered ambulatory systolic blood pressure to below $135 \mathrm{~mm} \mathrm{Hg}$ in 7 of these 10 patients with "true" resistant hypertension (Fadl Elmula et al., 2014). Therefore, patients with isolated systolic hypertension may be offered with adjusted drug treatment before being offered with renal denervation. 
In summary, renal denervation may not decrease ambulatory blood pressure in patients with isolated systolic hypertension. Adjusted drug treatment may be recommended to these patients before renal denervation, as the risk might overweigh the benefit of renal denervation in these patients.

\section{ACKNOWLEDGMENT}

Yutang Wang is supported by the National Health and Medical Research Council (1062671).

\section{REFERENCES}

Aguila, F. J., Mediavilla Garcia, J. D., Navarro, E. M., Vargas Hitos, J. A., and Fernandez-Torres, C. (2014). Bilateral renal artery stenosis after renal denervation. Hypertension 63, e126-e127. doi: 10.1161/HYPERTENSIONAHA.113.03065

Bacaksiz, A., Uyarel, H., Jafarov, P., and Kucukbuzcu, S. (2014). Iatrogenic renal artery stenosis after renal sympathetic denervation. Int. J. Cardiol. 172, e389-e390. doi: 10.1016/j.ijcard.2013.12.270

Bhatt, D. L., Kandzari, D. E., O'Neill, W. W., D'Agostino, R., Flack, J. M., Katzen, B. T., et al. (2014). A controlled trial of renal denervation for resistant hypertension. N. Engl. J. Med. 370, 1393-1401. doi: 10.1056/NEJMoa1402670

Bohm, M., Linz, D., Ukena, C., Esler, M., and Mahfoud, F. (2014). Renal denervation for the treatment of cardiovascular high riskhypertension or beyond? Circ. Res. 115, 400-409. doi: 10.1161/CIRCRESAHA.115.302522

Chandra, A. P., Marron, C. D., Puckridge, P., and Spark, J. I. (2014). Severe bilateral renal artery stenosis after transluminal radiofrequency ablation of renal sympathetic nerve plexus. J. Vasc. Surg. doi: 10.1016/j.jvs.2013.11.005. [Epub ahead of print].

Dolan, E., Stanton, A., Thijs, L., Hinedi, K., Atkins, N., McClory, S., et al. (2005). Superiority of ambulatory over clinic blood pressure measurement in predicting mortality: the Dublin outcome study. Hypertension 46, 156-161. doi: 10.1161/01.HYP.0000170138.56903.7a

Esler, M. D., Krum, H., Sobotka, P. A., Schlaich, M. P., Schmieder, R. E., and Bohm, M. (2010). Renal sympathetic denervation in patients with treatment-resistant hypertension (The Symplicity HTN-2 Trial): a randomised controlled trial. Lancet 376, 1903-1909. doi: 10.1016/S0140-6736(10)62039-9

Ewen, S., Ukena, C., Linz, D., Kindermann, I., Cremers, B., Laufs, U., et al. (2014). Reduced effect of percutaneous renal denervation on blood pressure in patients with isolated systolic hypertension. Hypertension. doi: 10.1161/HYPERTENSIONAHA.114.04336. [Epub ahead of print].

Fadl Elmula, F. E., Hoffmann, P., Larstorp, A. C., Fossum, E., Brekke, M., Kjeldsen, S. E., et al. (2014). Adjusted drug treatment is superior to renal sympathetic denervation in patients with true treatment-resistant hypertension. Hypertension 63, 991-999. doi: 10.1161/HYPERTENSIONAHA.114.03246

Hermida, R. C., Smolensky, M. H., Ayala, D. E., and Portaluppi, F. (2013). 2013 ambulatory blood pressure monitoring recommendations for the diagnosis of adult hypertension, assessment of cardiovascular and other hypertension-associated risk, and attainment of therapeutic goals. Chronobiol. Int. 30, 355-410. doi: 10.3109/07420528.2013. 750490

Kaltenbach, B., Id, D., Franke, J. C., Sievert, H., Hennersdorf, M., Maier, J., et al. (2012). Renal artery stenosis after renal sympathetic denervation. J. Am. Coll. Cardiol. 60, 2694-2695. doi: 10.1016/j.jacc.2012.09.027

Krum, H., Schlaich, M., Whitbourn, R., Sobotka, P. A., Sadowski, J., Bartus, K., et al. (2009). Catheterbased renal sympathetic denervation for resistant hypertension: a multicentre safety and proof-ofprinciple cohort study. Lancet 373, 1275-1281. doi: 10.1016/S0140-6736(09)60566-3

Lao, D., Parasher, P. S., Cho, K. C., and Yeghiazarians, Y. (2011). Atherosclerotic renal artery stenosisdiagnosis and treatment. Mayo Clin. Proc. 86, 649-657. doi: $10.4065 / \mathrm{mcp} .2011 .0181$

Persell, S. D. (2011). Prevalence of resistant hypertension in the United States, 20032008. Hypertension 57, 1076-1080. doi: 10.1161/HYPERTENSIONAHA.111.170308

Persu, A., Renkin, J., Thijs, L., and Staessen, J. A. (2012). Renal denervation: ultima ratio or standard in treatment-resistant hypertension. Hypertension 60, 596-606. doi: 10.1161/HYPERTENSIONAHA.112.195263

Pucci, G., Battista, F., Lazzari, L., Dominici, M., Boschetti, E., and Schillaci, G. (2014). Progression of renal artery stenosis after renal denervation. Circ. J. 78, 767-768. doi: 10.1253/circj.CJ13-0997

Staessen, J. A., Thijs, L., Fagard, R., O'Brien, E. T., Clement, D., de Leeuw, P. W., et al. (1999). Predicting cardiovascular risk using conventional vs ambulatory blood pressure in older patients with systolic hypertension. JAMA 282, 539-546.

Versaci, F., Trivisonno, A., Olivieri, C., Caranci, F., Brunese, L., and Prati, F. (2014). Late renal artery stenosis after renal denervation: is it the tip of the iceberg? Int. J. Cardiol. 172, e507-e508. doi: 10.1016/j.ijcard.2014.01.018

Vonend, O., Antoch, G., Rump, L. C., and Blondin, D. (2012). Secondary rise in blood pressure after renal denervation. Lancet 380, 778. doi: 10.1016/S01406736(12)61145-3

Worthley, S. G., Tsioufis, C. P., Worthley, M. I., Sinhal, A., Chew, D. P., Meredith, I. T., et al. (2013). Safety and efficacy of a multi-electrode renal sympathetic denervation system in resistant hypertension: the EnligHTN I trial. Eur. Heart J. 34, 2132-2140. doi: 10.1093/eurheartj/ eht197

Zhang, H. L., Sos, T. A., Winchester, P. A., Gao, J., and Prince, M. R. (2009). Renal artery stenosis: imaging options, pitfalls, and concerns. Prog. Cardiovasc. Dis. 52, 209-219. doi: 10.1016/j.pcad.2009.10.003

Conflict of Interest Statement: The author declares that the research was conducted in the absence of any commercial or financial relationships that could be construed as a potential conflict of interest.

Received: 31 October 2014; accepted: 03 December 2014; published online: 19 December 2014.

Citation: Wang Y (2014) Is isolated systolic hypertension an indication for renal denervation? Front. Physiol. 5:505. doi: 10.3389/fphys.2014.00505

This article was submitted to Integrative Physiology, a section of the journal Frontiers in Physiology.

Copyright (๑) 2014 Wang. This is an open-access article distributed under the terms of the Creative Commons Attribution License (CC BY). The use, distribution or reproduction in other forums is permitted, provided the original author(s) or licensor are credited and that the original publication in this journal is cited, in accordance with accepted academic practice. No use, distribution or reproduction is permitted which does not comply with these terms. 